\title{
Assessment of Rational Veterinary Drugs Use in Livestock at Adama District Veterinary Clinic, Central Ethiopia
}

Takele Beyene $^{1^{\star}}$, Sultan Assefa ${ }^{1}$, Dinka Ayana ${ }^{1}$, Tariku Jibat ${ }^{1}$, Fanos Tadesse ${ }^{1}$, Dereje Nigussie ${ }^{2}$ and Ashenafi Feyisa Beyi $^{1}$

${ }^{1}$ College of Veterinary Medicine and Agriculture, Addis Ababa University, PO Box 34, Bishoftu, Ethiopia

${ }^{2}$ Ethiopian Public Health Institute, Addis Ababa, Ethiopia

"Corresponding author: Takele Beyene, College of Veterinary Medicine and Agriculture, Addis Ababa University, PO Box 34, Bishoftu, Ethiopia, Tel: +251912828253; E-mail: takele.beyene@aau.edu.et

Rec date: Aug 10, 2015; Acc date: Mar 17, 2016; Pub date: Mar 19, 2016

Copyright: ( 2016 Beyene T, et al. This is an open-access article distributed under the terms of the Creative Commons Attribution License, which permits unrestricted use, distribution, and reproduction in any medium, provided the original author and source are credited.

\begin{abstract}
A retrospective study was conducted to evaluate rational drug use in livestock at Adama district veterinary clinic, central Ethiopia. 2,000 animal patients' encounters were randomly selected for the study from prescription registration books retrospectively. A total of 2,489 drug products prescribed for a total of 2,000 patients were assessed. The average number of drugs prescribed per encounter was 1.25 with maximum of three. The percentages of encounters in which antimicrobials $(A M)$ and anthelmintics $(A H)$ were prescribed were $46.4 \%$ $(1,156 / 2,489)$ and $46.7 \%(1,163 / 2,489)$, respectively. The percentages of drugs prescribed by generic name and from national veterinary drug list were $97.4 \%(2,424 / 2,489)$ and $100 \%$, respectively. The most commonly prescribed $\mathrm{AM}$ and $\mathrm{AH}$ were oxytetracycline $73.9 \%$ (854), penicillin and streptomycin fixed combination $22.6 \%(261)$ and ivermectin $94.8 \%(1,102)$, respectively. Among the total of 2,000 animal patient encounters, all (100\%) were treated empirically without getting correct laboratory supported diagnosis. Evaluation of drug prescription pattern based on clinical symptoms or disease diagnosed revealed that $\mathrm{AM}(22.6 \%)$ and $\mathrm{AH}(36.7 \%)$ were mostly prescribed for respiratory and musculoskeletal-integumentary systems, and gastrointestinal related clinical symptoms, respectively. The study result also showed AM (6.5\%) were prescribed for parasitic diseases whereas AH were administered for bacterial $(2.9 \%)$ and surgical $(0.9 \%)$ cases respectively. Among 2489 drugs prescribed by professionals, 1762 $(88.1 \%)$ and $238(11.9 \%)$ were done by animal health assistants and veterinarians, respectively. On the basis of the finding of this study, the prescribing practice for antimicrobials shows deviation from the standard recommended by $\mathrm{WHO}$. The findings had shown problems in generic prescribing, incorrect diagnosis and standardized patient case book with low prescribers' educational status in the study area. Therefore, veterinary drugs should be judiciously used; and a wide scale study to safeguard the public from drug residual effects and antimicrobial resistance development is recommended.
\end{abstract}

Keywords: Adama; Prescribing practices; Rational use; Retrospective; Veterinary drugs

\section{Abbreviations \\ ADARDO: Adama agricultural and rural development office; DACA: Drug administration and control authority; EVDL: National veterinary drug list of Ethiopia; NMSA: National metrological service agency; STG: Standard treatment guideline; WHO: World health organization.}

\section{Introduction}

Veterinary drugs are used in livestock sector either rationally or irrationally as therapeutic, prophylactic, and growth promotion. Rational use of drugs is based on the use of right drug, at right dosage, right cost and right time which is well reflected in the world health organization (WHO) whereas irrational use of drugs is defined as "too many medicines are prescribed per patient, injections are used where oral formulations would be more appropriate, antimicrobials are prescribed in inadequate doses or duration, antibiotics prescribed for non-bacterial infections, prescriptions do not follow clinical guidelines and self-medicate inappropriately or do not adhere to prescribed treatment" [1].
Antimicrobials are used in the clinical practice of human and veterinary medicine throughout the world. Most failures during antimicrobial therapy may occur when the pathogenic microorganism is unknown and combination of two or more drugs administered empirically. To avoid these mistakes, clinically confirmed, effective antimicrobial combinations should be used [2].

Improper use of drugs may cause ineffective treatment, unnecessary wastage of resources, and may harm the patient [3]. Irrational use of drugs in veterinary medicine, and the need for control of their use becomes even bigger problem when used on food producing animals. Here, there is the possibility that minimal quantities of drugs and their metabolites (residues) which remain in edible tissues or in animal products (meat, milk, eggs, honey) induce certain harmful effects in humans as potential consumers of such food [4]. To prevent this risk it is necessary to use drugs rationally, i.e., to use them only when they are really indicated, in the right way, at the right time, in the right dose and respecting withdrawal period. Additionally, it should regularly control sensitivity to antimicrobial agents and regulate residue of antimicrobial agents commonly used in veterinary practice $[2,5]$.

Rational approach to therapeutics requires careful evaluation of the health problem in each species of animals and selecting appropriate therapeutic strategies [6,7]. Selection of treatment requires cost/benefit analysis particularly in food animals. Its efficacy, safety with minimal 
adverse effects and minimal residues in food animals should be also given due attention. Drug choice depends on individual patient and prescription; whenever written it should indicate species of animal, the age, sometimes breed, the dose of the drug in the formulations available locally and the duration of treatment [3,7]. Advice on nutritional support and nursing care are also very important to ensure rational therapeutics [7].

Over use of antimicrobials [8] and anthelmintics [9] in veterinary medicine, for both food producing and companion animals, favours the development of antimicrobial and anthelmintic resistance. This drug resistance is a growing problem; and some of the common causes that contribute to the development of antimicrobial resistance are unnecessary use of antimicrobial drugs, inappropriate dose, inadequate duration of therapy, use of irrational antimicrobial fixed dose drug combinations [10].

In humans, assessments of drug use patterns with the WHO drug use indicators are becoming increasingly necessary to promote rational drug use [11,12]. In Ethiopia, a survey conducted on human subjects at hospitals revealed irrational drug use [13-15]. Similarly, in veterinary medicine, a study conducted by Beyene et al. [16] on rational use of veterinary drugs at veterinary teaching hospital of the college of veterinary medicine and agriculture, and Ada district veterinary clinic showed irrational drug use. Hence, the present study evaluated the rational use of commonly used veterinary drugs in veterinary clinical practices and to compare the magnitudes of drugs commonly used to treat livestock diseases at Adama district veterinary clinic, central Ethiopia.

\section{Materials and Methods}

\section{Study area and period}

The study was conducted from November 2013 to May 2014 at Adama district veterinary clinic, central Ethiopia. Adama is in Oromia regional state in East Shoa zone at about $99 \mathrm{~km}$ south east of Addis Ababa $\left(39.17^{\circ} \mathrm{E}\right.$ and $\left.8.33^{\circ} \mathrm{N}\right)$ with an altitude of 1622 meters above sea level in the rift valley. Its annual rainfall ranges from $400 \mathrm{~mm}$ to 800 $\mathrm{mm}$ and has a temperature of $13.9^{\circ} \mathrm{C}$ to $27.7^{\circ} \mathrm{C}[17,18]$.

\section{Study design}

A retrospective and cross-sectional study was designed to assess rational drug use and to compare commonly used drugs to treat animal diseases at Adama district veterinary clinic. The sample was selected using a systematic random sampling method, and the sampling unit was animal patient encounters at Adama district veterinary clinic to treat acute and/or chronic illness. Then drug use was evaluated based on WHO drug use indicators as described in WHO [1].

\section{Study population}

The study was conducted between November 2013 to May 2014 on animals/patients (cattle, sheep, goats, equines, pets and chicken of all ages and sex groups) that were admitted to Adama district open-air veterinary clinic and treated with drugs. All animal patients that admitted to veterinary clinic but received none medicines were excluded from the study.

\section{Data collection}

An excel sheet data collection format was designed and then data was collected on prescribing indicators retrospectively by using patient case registration books in Adama district veterinary clinic. The specific data necessary to measure the prescribing indicators were recorded for each animal patient encounter and entered into an ordinary prescribing indicator form. For this study, 2,000 prescriptions that contain the animal's characteristics (age, sex, breed, body condition, clinical signs and symptoms observed); disease diagnosis (name, empiric or physical clinical examination and confirmatory laboratory tests used); prescribed drugs (type, naming [generic or brand], number of drugs prescribed, route of administration, duration of treatment, availability in the national veterinary drug list); and prescriber's signature, level of education and years of experiences were collected retrospectively from more than 5,000 prescriptions written for 2 years period from January 01, 2012 to December 31, 2013. The availability of both veterinary treatment guidelines and national veterinary drug list (EVDL) in the clinic were also observed. Accordingly, evaluation of rational use of veterinary drugs was made on the basis of generic prescription, and antimicrobials and anthelmintics prescribed for tentatively diagnosed clinical cases.

\section{Data analysis}

All data in the ordinary prescribing indicator recording form were entered into Microsoft Excel spread sheet (version 2010) and imported and analysed using SPSS (Version 20). Means, median (range), and frequencies (percentage) were used to describe patients' characteristics was determined to compare with the standard recommended by WHO. Chi-square test was used to compare categorical variables where appropriate or to determine the association between drug prescribed and clinical symptom observed, and drug prescribed and disease diagnosed. All statistical tests were two sided, and P-values $\leq$ 0.05 was significant.

\section{Ethical considerations}

The study was granted an exemption from requiring ethical approval from the College of Veterinary Medicine and Agriculture Institutional Research and Review Board Committee. The researchers got permission for access to data from the Office of Adama District Veterinary Clinic. Confidentiality of the patients' data and prescribers was maintained by using unique code.

\section{Prescribing indicators}

There was no available guideline for prescribing indicators used in veterinary medicine. As a result the WHO prescribing indicators were used in this study [19]. The indicators were pretested, and slightly modified to match with clinical practice in veterinary medicine so they could be used to provide accurate data. The final versions of the pretested indicators are:

1. The average number of drugs prescribed per encounter was calculated by dividing the total number of different drug products prescribed with the number of encounters surveyed to measure the degree of polypharmacy. Fixed combinations of drugs prescribed for one health problem were counted as one;

2. Percentage of drugs prescribed by generic name were calculated by dividing the number of drugs prescribed by generic name with total 
Page 3 of 7

number of drugs prescribed, multiplied by 100 to measure the tendency of prescribing by generic name;

3. Percentage of encounters in which antimicrobials, anthelmintics, and other drugs prescribed were calculated by dividing the number of patient encounters in which drug was prescribed with the total number of encounters surveyed, multiplied by 100 to measure the overall use of overused (irrationally prescribed) and costly forms of drug therapy; and

4. Percentage of drugs prescribed from national veterinary drug list of Ethiopia (EVDL) was calculated by dividing number of products prescribed which are in veterinary drug list with the total number of drugs prescribed, multiplied by 100 to measure the degree to which the practices conform to a national drug policy as stated in the EVDL of Ethiopia [20].

5. Rational use of veterinary drugs means the sick animals receive medications appropriate to their clinical needs, in doses that meet their own individual requirements, for an adequate period, and at the lowest cost to them and their community [21,22] whereas irrational use of drug means misuse of drugs by the patient (i.e., patients receive medications inappropriate to their clinical needs, under or over dosing that meet their own individual requirements, and for inadequate period of time) [22].

\section{Results}

A total of 2,000 patients' profiles from casebook were assessed at Adama district veterinary clinic. The retrospective study has shown that 2,489 drug products were prescribed, and the average number of drugs per prescription was 1.25 with maximum of three drugs. The total number of drugs prescribed by generic name was $1,948(97.4 \%)$ and the remaining $52(2.6 \%)$ treatment was prescribed with drugs in their brand name. All drugs were prescribed $(n=2,489,100 \%)$ from the EVDL.

The rational drug use evaluation has shown that antimicrobials, anthelmintics, antimicrobial-anthelmintic combinations, and other drugs were prescribed for 2,000 patients admitted to the clinic. Out of the total 2,489 drugs prescribed, $1,156(46.4 \%)$ antimicrobials, 1,163 (46.7\%) anthelmintics, and 170 (6.8\%) other drugs [acaricides, vitamins, gastrointestinal stimulants and anti-inflammatory drugs] were prescribed. The most commonly prescribed antimicrobials and anthelmintics were oxytetracycline 854 (73.9\%), penicillinstreptomycin fixed combination 261 (22.6\%), sulfa drugs (sulfadimidine and sulphametoxazole-trimethoprim fixed combination) 33 (2.9\%), and ivermectin 1102 (94.8\%), albendazole 16 (1.4\%), triclabendazole (fascinex) $20(1.7 \%)$, tetraclozan $19(1.6 \%)$ and others $6(0.5 \%)$ (Table 1$)$.

\begin{tabular}{|l|l|l|}
\hline Therapeutic agent Class & Frequency & Percentage of subtotal \\
\hline Antimicrobials & & \\
\hline Oxytetracycline & 854 & $73.90 \%$ \\
\hline Penstrep & 261 & $22.60 \%$ \\
\hline Sulphonamide & 33 & $2.90 \%$ \\
\hline Procaine penicillin & 5 & $26.60 \%$ \\
\hline Intra mammary infusion & 2 & $0.20 \%$ \\
\hline Gentamycin & 1 & $0.10 \%$ \\
\hline
\end{tabular}

\begin{tabular}{|l|l|l|}
\hline Subtotal & 1156 & $100 \%$ \\
\hline Anthelmintics & & \\
\hline Ivermectin & 1102 & $94.80 \%$ \\
\hline Triclalbendazole(fascinex) & 20 & $1,7 \%$ \\
\hline Tetraclozan & 19 & $1.60 \%$ \\
\hline Albendazole & 16 & $1.40 \%$ \\
\hline Tinidazole & 4 & $0.30 \%$ \\
\hline Subtotal & 1163 & $100 \%$ \\
\hline Other drugs & & \\
\hline Vitamins & 37 & $21.80 \%$ \\
\hline Iv nutrition & 27 & $15.90 \%$ \\
\hline Furosemide & 25 & $14.70 \%$ \\
\hline Pain killers & 21 & $12.40 \%$ \\
\hline Antiseptics & 18 & $10.60 \%$ \\
\hline Laxative & 17 & $10.00 \%$ \\
\hline Diaminazine aceturate & 9 & $5.30 \%$ \\
\hline Rare* & 16 & $9.40 \%$ \\
\hline Subtotal & 170 & $100 \%$ \\
\hline Total & 2489 & \\
\hline
\end{tabular}

Table 1: Therapeutic classification of drugs commonly prescribed in Adama district veterinary clinic during 2012 and 2013. Rare*: Ichthammol (1.8\%), Atropine sulphate (1.2\%), indigestion oil (1.2\%), antifungal (1.2\%), acaricide (1.2\%), copper sulphate (1.2), indigestion powder $(0.6 \%)$.

Among 2,000 patients admitted to the clinic to get treatment, all $(100 \%)$ were treated empirically, without getting correct definitive (laboratory supported) diagnosis though some were diagnosed based on pathognomonic and specific clinical signs rather than confirmatory laboratory tests. The routes of drug administration were not written for $99.1 \%(2466 / 22489)$ of the prescribed drugs. Additionally, there were no any record about the history of pretreatment, standard prescription paper and standard treatment guidelines and only few essential drugs were available at Adama district veterinary clinic although the duration of administration of these drugs were also not specified for 93.5\% of the cases.

Evaluation of the association between drug prescription and clinical symptoms revealed that antimicrobials (22.6\%) and anthelmintics $(36.7 \%)$ were mostly prescribed for respiratory and musculoskeletalintegumentary systems, and gastrointestinal related clinical symptoms than for other clinical signs, respectively. Anthelmintics (0.5\%) were also prescribed for clinical signs related with urogenital system with pvalue of 0.03 (Table 2). The association between drug administered and diseases diagnosed was also assessed to see the rational prescription pattern. The study result showed $2.9 \%$ and $0.9 \%$ anthelmintics were administered for bacterial and surgical diseases respectively whereas antimicrobials $(6.5 \%)$ was prescribed for parasitic diseases with a pvalue of 0.001 (Table 3 ). 


\begin{tabular}{|c|c|c|c|c|c|c|c|c|}
\hline \multirow[b]{2}{*}{ Drug prescribed } & \multicolumn{8}{|c|}{ Clinical symptoms (\%) } \\
\hline & RS & DG & UG & MS and G & $\mathrm{CV}$ and $\mathrm{G}$ & $\begin{array}{l}\text { RS } \\
\text { and DG }\end{array}$ & RS, MS and G & DG, MS and G \\
\hline \multirow{2}{*}{$A B$} & 85 & 49 & 7 & 103 & 112 & 45 & 154 & 125 \\
\hline & $-12.50 \%$ & $-7.20 \%$ & $-1.20 \%$ & $-15.10 \%$ & $-16.40 \%$ & $-6.60 \%$ & $-22.60 \%$ & $-18.40 \%$ \\
\hline \multirow{2}{*}{$\mathrm{AH}$} & 21 & 28 & 3 & 208 & 123 & 6 & 30 & 244 \\
\hline & $-3.20 \%$ & $-4.20 \%$ & $-0.50 \%$ & $-31.30 \%$ & $-18.50 \%$ & $-0.90 \%$ & $-4.50 \%$ & $-36.70 \%$ \\
\hline \multirow{2}{*}{ AB-AH } & 69 & 101 & 2 & 64 & 48 & 37 & 43 & 128 \\
\hline & $-14 \%$ & $-20.50 \%$ & $-0.40 \%$ & $-13.00 \%$ & $-9.80 \%$ & $-7.50 \%$ & $-8.70 \%$ & $-26.00 \%$ \\
\hline \multirow{2}{*}{ Others } & 1 & 10 & 26 & 42 & 26 & 1 & 25 & 28 \\
\hline & $-0.60 \%$ & $-6.20 \%$ & $-16.20 \%$ & $-26.20 \%$ & $-16.20 \%$ & $-0.60 \%$ & $-15.60 \%$ & $-17.50 \%$ \\
\hline
\end{tabular}

Table 2: Common animal clinical signs and symptoms at Adama district veterinary clinic and their drug administration. $\chi^{2}=619.87, \mathrm{P}$-value $=0.03$. AB: Antibiotics; AH: Anthelmintics; AB-AH: Antibiotic and anthelmintic combination; CV: Cardiovascular; DG: Digestive; IG: Integumentary; G: Generalized; MS: Musculoskeletal; RS: Respiratory; UG: Urogenital.

\begin{tabular}{|c|c|c|c|c|c|c|}
\hline \multirow[t]{2}{*}{ Drug administered } & \multicolumn{6}{|c|}{ Disease category (\%) } \\
\hline & Bacterial & Viral & Parasitic & Metabolic & Surgical & Miscellaneous \\
\hline$A B$ & $52.1 \%$ & $16.2 \%$ & $6.5 \%$ & $0.6 \%$ & $5.6 \%$ & $18.9 \%$ \\
\hline $\mathrm{AH}$ & $2.9 \%$ & $0.0 \%$ & $91.7 \%$ & $0.0 \%$ & $0.9 \%$ & $4.5 \%$ \\
\hline AB-AH & $38.4 \%$ & $7.3 \%$ & $14.2 \%$ & $0.6 \%$ & $3.0 \%$ & $36.4 \%$ \\
\hline Others & $3.1 \%$ & $1.2 \%$ & $13.7 \%$ & $31.2 \%$ & $36.2 \%$ & $14.4 \%$ \\
\hline
\end{tabular}

Table 3: Common animal diseases/conditions diagnosed based on clinical signs and symptoms at Adama district veterinary clinic and their association with drug administration. $\chi^{2}=2205.1$, P-value $=0.001$. AB: Antibiotics; AH: Anthelmintics; AB-AH: Antibiotic and anthelmintic combination.

The educational level of the prescribers was also assessed. One thousand seven hundred sixty two (88.1\%) and 238 (11.9\%) of the prescriptions were done by animal health assistants and veterinarians, respectively.

\section{Discussion}

In this study, the average number of drugs per prescription at Adama district veterinary clinic was 1.25 . This finding is in accordance with the study conducted by Beyene et al. [16] at veterinary teaching hospital of the college of veterinary medicine and agriculture (VTHCVMA) and Ada district veterinary clinic, who reported 1.23. However, the WHO standard for humans is 1.6-1.8 [12,23] that shows polypharmacy was not found to be a problem. A national baseline study done on drug use indicators of humans in Ethiopia in September 2002 also showed the average number of drugs prescribed per encounter was 1.9 [24], which is above our finding. However, in other study conducted in northern Ethiopia at Gondar Hospital showed the average number of drugs per patient was 0.98 [24], which is lower than this finding. A high average number of drugs on humans might be due to financial incentives to prescribers to prescribe more, lack of therapeutic training of prescribers, or shortage of therapeutically correct drugs [19]. However, the low values in Adama district veterinary clinics might mean there is constraint of drugs rather than beliefs of prescribers have appropriate training in therapeutics.

The percentage of drugs prescribed by generic name in the present study $(97.4 \%)$ slightly deviates from the standard derived to serve as ideal (100\%) as stated by Isah et al. as drugs need to be prescribed only in their generic name. However, the finding of the present study revealed a higher generic drug prescription pattern than $90.1 \%$ reported by Beyene et al.

The drug prescription pattern revealed antimicrobials (46.4\%), anthelmintics (46.8\%) and other drugs (6.8\%) were prescribed to treat animal patients in this study area. Among anthelmintics, Ivermectin $1102 / 2489(44.3 \%)$ was a commonly prescribed drug in this study. However, the study conducted by Beyene et al. [16] revealed $54.4 \%$ antimicrobials, $38.9 \%$ anthelmintics and $6.7 \%$ others drugs were prescribed at VTH-CVMA and Ada district veterinary clinic, where albendazole 732/2235 (32.8\%) was the commonly used anthelmintics.

The major considerations for proper usage of antimicrobial agents, which are a main concern of modern medicine, are to select the optimal agent at the proper dosage and duration, to minimize the emergence of resistance and to provide health services at a reasonable cost [25]. There is no any report that supports the ideal standard 
percentage of encounters in which antibiotics were prescribed for animals. However, in humans $20.0 \%-26.8 \%$ of antibiotics were prescribed [12,32]. There is considerable evidence that antimicrobial agents are often abused and used excessively, in this study 1,156/2,489 (46.4\%) of the prescriptions were antibiotics. The findings of the present study revealed a lower rate of antibiotics prescription than $54.4 \%$ reported by Beyene et al. [16]. Moreover, although a review done by Alemu et al. [26] indicates that many infectious agents have developed resistance against oxytetracycline antibiotic, oxytetracycline $854(73.9 \%)$ and penstrep $261(22.6 \%)$ are the most prescribed antibiotics observed in current study. Similarly, these two antibiotics were commonly used as reported in previous study conducted by Beyene et al. [16] $83.6 \%$ and $13.8 \%$ respectively.

Overuse of antibiotics is an indication of a problem because it could facilitate emergence of resistance bacterial strains [27]. Ideally, good antibiotic prescribing practice should reflect the use of the most effective, least toxic, and least costly antibiotic for the precise duration of time needed to cure the infection $[28,29]$. Unfortunately, according to the study conducted by Gyssens [29] up to $40 \%$ to $60 \%$ of the antibiotics were prescribed inappropriately (WHO), which is consistent with our findings (46.4\%). The high percentage of antibiotics prescribed in this study may be due to lack of knowledge of the prescriber about microbial drug resistance, animal owners' expectation to receive antibiotics influencing the prescriber, or prescribers' belief that the therapeutic efficacy of antibiotics is low. A national baseline study on drug use indicators for human subjects in Ethiopia also showed that the percentage of encounters in which an antibiotic was prescribed to be $58.1 \%$ [30], which was above our finding. Overuse of antibiotics indicated irrationality, because it could facilitate emergence of resistance. Moreover, the cost incurred is high due to extravagant prescribing where drugs are prescribed for viral infection or for infections in which symptomatic treatment is enough. In addition, empirical treatment was also a problem, where two or more drugs were prescribed but one specific antibiotic is enough after proper diagnosis.

The primary purpose of veterinary drugs is to safeguard the health and welfare of animals [31]. All of the cases (100\%) encountered at Adama district veterinary clinic received drug therapy after they had been tentatively diagnosed. For instances, antimicrobials were prescribed irrationally to treat diseases that were tentatively diagnosed as respiratory and musculoskeletal-integumentary systems (27.5\%), gastrointestinal parasitosis (6.5\%), to prevent secondary bacterial complications from viral diseases (16.2\%) and for surgical cases (5.6\%). Using antimicrobial agent for parasitic disease was inappropriate and needs careful consideration to solve this problem. The use of antimicrobial during and after surgery is a substitute for clean surgery and could be avoided to decrease extra expense. If the surgeon practices clean surgery and follows correct procedures, antimicrobial are not necessary. This irresponsible prescription problem had occurred may be due to lack of knowledge, overworked veterinary assistants in need of rest. This requires strict consideration by the concerned veterinary authority. Additionally, the use of anthelmintics for clinical signs related with urogenital systems $(0.5 \%)$, and for bacterial diseases (2.9\%) and surgical cases (0.9\%) could result in economic losses for the animal owners.

Furthermore, not specifying the routes of drug administration for $99.1 \%$ of the prescribed drugs reveals irrational drug use. These problems may arise from lack of basic medical knowledge and laboratory tests or careless diagnosis without following routine clinical examination. Hence, careful attention has to be given for case confirmatory laboratory diagnosis to avoid misuse of chemotherapeutic agents.

Drugs are the most frequently detected chemical residues in foods of animal origin, overwhelmingly majority of which are antimicrobials [32] commonly used in veterinary practice in this study. Drug residues in animal-derived food products are an important consideration for consumers as it may favours the emergence of resistant microbial strains within a host as well as by being of allergenic, toxic, mutagenic, teratogenic, or carcinogenic [33].

An assessment made to determine the educational qualification of the drug prescribers revealed that majority of the prescribers in the clinic were animal health assistants (88.1\%) or diploma level and only $11.9 \%$ were veterinarians. This study is in line with similar study conducted by Beyene et al. [16] at VTH-CVMA and Ada district veterinary clinic, where $70.8 \%$ and $29.2 \%$ of the prescriptions were done by animal health assistants and veterinarians, respectively. This shows that the level of education of veterinary drug prescribers is low and needs attention so as to avoid failure of treatment, misuse of drugs and drug resistance development. The Ethiopian federal constitution under proclamation no 728-2011 stated that veterinary drugs shall only be prescribed by a veterinarian. It also stated that a veterinarian shall prescribe veterinary drugs following prescription procedures and on standard prescription paper [34].

By far the clinic was not using any laboratory tests at all. The result is similar to the study done by Beyene et al. [16] $96.6 \%$ of patients admitted to CVMA-VTH and Ada district veterinary clinic were treated empirically, without getting correct definitive (laboratory supported) diagnosis. This shows that diseased animals are treated based only on tentative diagnosis which implies that the diseased animals do not managed with meticulous treatment, or drugs used irrationally without knowing the particular cause of the disease i.e., whether it is bacterial, parasitic or any other etiological agents. The clinic also was not recording the history of pretreatment, and hence drugs used repeatedly for the same animal. This largely contributes for the development of drug resistance in animals and also in humans who consumes them and their products.

The other problem of this clinic which has a great effect on use of drugs was that, the clinicians did not write or specify route of administration, i.e., (99.1\%) of prescribed drugs route of administration was not specified. This problem needs to be regulated by the concerned body. Moreover, other issue associated with the rational drug use was that the clinic does not have standard prescription paper, instead they used prescription handling book which did not contain full information about the routine clinical examination and treatment. Age, sex, clinical signs observed, sometimes body condition, tentatively diagnosed disease name and drug name were the only written information on book. However, these are not sufficient for routine clinical examination and treatment.

The length of treatment of $93.5 \%$ encounters or cases was not specified. This may shows that drugs were administered without following standard treatment guideline. Animals treated either with under dose or over dose. This act also has contribution for the development of antibiotic resistance and economic loss to the owner and the country at large.

The most important educational material for prescribers is the standard treatment guideline (STG), which are essential particularly most effective among untrained health workers [35]. For instances, the 
study conducted in Kenya showed introducing STGs for malaria (before/ after study design) resulted in a sharp drop in unnecessary quinine use [36]. However, this educational material was not available for professionals in the study area. Hence, relevant guidelines and other drug information sources must be present in hand of every veterinary professionals for prudent use of chemotherapeutic agents and to success of voluntary measures take to minimize drug resistance [37] and their proper application should be enforced by law. Besides, the availability of an essential drug list (EVDL) is very important for the accuracy and rationality of treatment or prescription. A randomized controlled study in Yemen showed that after introduction of EVDL, rational drug knowledge of prescribers increased significantly, as well as actual drug prescribing for three indicators [38]. In Ethiopia, the introduction of EVDL resulted in a significant decrease of non-essential drug prescribing [39]. Subject to many underlying factors, the widely spread irrational use of veterinary drugs needs to be tackled through various interventions, including the introduction of guidance on the use of drugs. Though formulary for veterinary drugs is believed to be one of the key guiding instruments for the facilitation of the promotion of rational use [20], it was not used in Adama district veterinary clinic [40-44].

\section{Study limitation}

The study is illumining the presence of irrational veterinary drug usage at Adama district veterinary clinic. However, the study has some limitations as cases were not specified properly (e.g., respiratory diseases, GIT disturbances and reproductive problems) and mainly based on tentative diagnosis. Confirmatory laboratory tests were also not done for all cases. As a result, evaluation of rational use of veterinary drugs for various clinical cases or animal diseases was made based on clinical signs and symptoms.

\section{Conclusions}

The findings of the present study on veterinary drugs prescribing practices have showed that there were problems of correct diagnosis and drug administration based on clinical signs observed and diseases diagnosed, lack of laboratory tests, low prescribers' educational status, lack of standard veterinary treatment guide lines, presence of few essential drugs, absence of standard case paper which has to contain all necessary information of routine clinical examination and treatments, and the non-availability of both standard veterinary treatment guideline and drug formulary in the study area, could lead to irrational drug use. On the other hand, polypharmacy and prescribing from EVDL were not found to be a problem. The data gathered in the present study can be used by researchers and policymakers to improve drug prescribing practice in veterinary medicine. The government, private animal health care institutions, individual animal health care providers and animal owners all have a responsibility to promote rational use of veterinary medicines. Hence, integrated national databases to support a rational use of antimicrobials in food animals, which would ensure the effectiveness of these drugs and the safety of foods of animal origin, should be established.

\section{Competing Interests}

The authors declare that they have no competing interests.

\section{Authors' Contributions}

$\mathrm{TB}, \mathrm{TJ}$ and AF developed the research idea. TB and SA took part in collecting the data. TB, DA, YH and AF coordinated and supervised the study. TB and AF provided valuable information on the subject of data analysis and the design of the study. SA, TB and DN participated in writing the draft manuscript. TB revised the draft version of the manuscript. All authors have read and approved the final manuscript.

\section{Acknowledgements}

The researchers would like to thank Addis Ababa University for the research fund. We also acknowledge the priceless support given by Adama district veterinary clinic for allowing us to use all available patient records.

\section{References}

1. WHO (2012) Rational use of medicines. World Health Organization.

2. Vitomir C, Silva D, Biljana A, Sanja C (2011) The significance of rational use of drugs in veterinary medicine for food safety. Tehnologija mesa 52: 74-79.

3. DACA (2006) Standard treatment guidelines for veterinary practice. (1st edn) Drug administration and control authority of Ethiopia, Addis Ababa, Ethiopia:

4. Sanders P (2007) Veterinary drug residue control in the European Union. Technologija mesa 1: 59-68.

5. Barbosa J, Cruz C, Martins J, Silva JM, Neves C, et al. (2005) Food poisoning by clenbuterol in Portugal. Food Addit Contam 22: 563-566.

6. Matter D, Rossano A, Limat S (2007) Antimicrobial resistance profile on actinobacillus pleuropneumoniae and actinobacillus porcitonsillarum. Vet microbial 122: 144-156.

7. Rehan HS, Singh C, Tripathi CD, Kela AK (2001) Study of drug utilization pattern in dental OPD at tertiary care teaching hospital. Indian J Dent Res 12: 51-56.

8. VMD (2008) Assuring the safety, quality and efficacy of veterinary drugs. Sales of antimicrobial products for use as veterinary medicines, antiprotozoals, antifungals, growth promoters and coccidiostats in the UK in 2007, UK.

9. Geary TG, Woo K, McCarthy JS, Mackenzie CD, Horton J, et al. (2010) Unresolved issues in anthelmintic pharmacology for helminthiases of humans. Int J Parasitol 40: 1-13.

10. Soulsby EJ (2005) Resistance to antimicrobials in humans and animals. BMJ 331: 1219-1220.

11. Laing R, Hogerzeil H, Ross-Degnan D (2001) Ten recommendations to improve use of medicines in developing countries. Health Policy Plan 16: 13-20.

12. WHO (1993) World Health Organization. How to investigate drug use in health facilities: selected drug use indicators. WHO, Geneva.

13. Getachew E, Solomon A, Wuletaw A, Asrat Agalu (2013) Antibiotic prescribing pattern in a referral hospital in Ethiopia. Afr J Pharm Pharmacol 7: 2657-2661.

14. EPA (2003) Assessment of the Pharmaceutical Sector in Ethiopia, Addis Ababa.

15. Abdulahi M, Shiferaw T (1997) Pattern of prescription in Jimma Hospital. Ethiop J Health Dev 11: 263-267.

16. Beyene T, Endalamaw D, Tolossa Y, Feyisa A (2015) Evaluation of rational use of veterinary drugs especially antimicrobials and anthelmintics in Bishoftu, Central Ethiopia. BMC Res Notes 8: 482.

17. ADARDO (2003) Adama agricultural and rural development office, Adama, Ethiopia.

18. NMSA (2006) National metrological service agency, Adama, Ethiopia.

19. Desalegn AA (2013) Assessment of drug use pattern using WHO prescribing indicators at Hawassa University Teaching and Referral 
Citation: Beyene T, Assefa S, Ayana D, Jibat T, Tadesse F, et al. (2016) Assessment of Rational Veterinary Drugs Use in Livestock at Adama District Veterinary Clinic, Central Ethiopia . J Veterinar Sci Techno 7: 319. doi:10.4172/2157-7579.1000319

Page 7 of 7

Hospital, south Ethiopia: a cross-sectional study. BMC Health Serv Res 13: 170 .

20. DACA (2002) List of veterinary drugs for Ethiopia. (1st edn) Drug Administration and Control Authority of Ethiopia, Addis Ababa, Ethiopia.

21. Beyene T, Tesega B (2014) Rational veterinary drug use: Its significance in public health. JVMH 6: 302-308.

22. Hanmant A, Priyadarshini K (2011) Prescription analysis to evaluate rational use of antimicrobials. Int J of Pharmacol and Biol Sci 2: 314-319.

23. Isah A, Ross-Degnan D, Quick J, Laing R, Mabadeje A (2004) The development of standard values for the WHO drug use prescribing indicators. ICIUM.

24. Tunger O, Karakaya Y, Cetin CB, Dinc G, Borand H (2009) Rational antibiotic use. J Infect Dev Ctries 3: 88-93.

25. Niederman MS (2005) Principles of appropriate antibiotic use. Int J Antimicrob Agents 26 Suppl 3: S170-175.

26. Alemu T, Eyasu M, Solomon G, Tenaw A, Yilkal A (2009) Literature review on infectious diseases, antimicrobial use, resistance and containment. In: Antimicrobial use, resistance, and containment baseline survey syntheses of findings. Drug Administration and Control Authority of Ethiopia in collaboration with Management Sciences for Health, Strengthening Pharmaceutical Systems (MSH/SPS), Addis Ababa, pp: $37-42$.

27. Till B, Williams L, Oliver SP, Pillans PI (1991) A survey of inpatient antibiotic use in a teaching hospital. S Afr Med J 80: 7-10.

28. WHO (2002) promoting rational use of medicines: core components. WHO Policy and Perspectives on medicine, World Health Organization, Switzerland, Geneva, pp: 12-14.

29. Gyssens IC (2001) Quality measures of antimicrobial drug use. Int J Antimicrob Agents 17: 9-19.

30. WHO (2003) Assessment of the Pharmaceutical Sector in Ethiopia. World Health Organization, Addis Ababa.

31. Cannavan A (2004) Capacity Building for Veterinary Drug Residue Monitoring Programmes in Developing Countries. Joint FAO/WHO Workshop on Residues of Veterinary Drugs without ADI/MRL Bangkok.

32. Dowling PM (2013) Antimicrobial drug residues in foods of animal origin. In: Giguere S, Prescott JF, Dowling PM (eds.) Antimicrobial therapy in Veterinary Medicine (5th edn) Blackwell Publishing, Iowa, pp: 431-441.

33. Riviere JE, Sundlof SF (2001) Chemical residue in tissues of food animals. In: Adams HR (eds) Veterinary Pharmacology and Therapeutics (8th edn) Blackwell Publishing Professional, Iowa 26: 1166-1174.

34. Federal Negarit Gazeta of the Federal Democratic Republic of Ethiopia (2012) Prescription and Dispensing of Veterinary Drugs. Veterinary Drug and Feed Administration and Control Proclamation. Federa Negarit Gazeta 14: 6271 .

35. Kafuko JM, Zirabumuzaale C, Baganda D (1994) Rational drug use in rural health units of Uganda: Effect of national standard treatment guidelines on rational drug use. WHO.

36. Nabiswa AK, Makokha JD, Godfrey RC (1993) Malaria: impact of a standardized protocol on inpatient management. Trop Doct 23: 25-26.

37. Gertraud R, Kay TB, Beat GF (2009) Prescription patterns of antimicrobial in veterinary practices in Geneva, Switzerland. J Antimicrob Chemo 16: 19-25.

38. Hogerzeil HV, Walker GJ, Sallami AO, Fernando G (1989) Impact of an essential drugs programme on availability and rational use of drugs. Lancet 1: 141-142.

39. Lindtjørn B (1987) Essential drug list in a rural hospital. Does it have any influence on drug prescription. Trop Doct 17: 151-155.

40. Adams HR (2001) Veterinary Pharmacology and Therapeutics. (8th edn), Iowa State University Press/Ames pp: 125-143.

41. Bekele T (1999) Transformation of the vet service in Ethiopia. Proceedings of the 10th conference Ethiopian Veterinary Association, Addis Ababa, Ethiopia.

42. Bimo D (1992) Report on Nigerian field test. In: How to investigate drug use in health facilities. Geneva: WHO, INRUD News 3: 9-10.

43. Bren L (2006) Animal health and consumer protection. US Food and Drug Administration, FDA Consumer magazine.

44. Desta Z, Abula T, Gebre-Yohannes A, Worku A (2002) Drug prescribing patterns for outpatients in three hospitals in north-west Ethiopia. Ethiop J Health Dev 16: 183-189. 